\title{
Propriedades de painéis aglomerados produzidos com resíduos do processamento mecânico da madeira
}

O objetivo do estudo foi avaliar as propriedades físicas e mecânicas, de painéis aglomerados confeccionados com partículas provenientes de resíduos do processamento mecânico da madeira de Schizolobium amazonicum Huber ex. Ducke (Paricá), tendo como aglutinante o adesivo de silicato de sódio. 0 delineamento utilizado foi o inteiramente casualizado, com 12 tratamentos e quatro repetições, totalizando 48 painéis. Os ensaios foram realizados de acordo com as normas ABNT/NBR 14810-3(2002) e ANSI/A-208.1(1999). As médias foram comparadas pelo teste Tukey para o coeficiente de esbeltez das partículas e pelo teste de Scott-Knott para as propriedades físicas e mecânicas, adotando-se $5 \%$ de significância para ambos $(p=0,05)$. Além disso, foi verificada a correlação da massa específica com os demais ensaios utilizando-se os coeficientes de Pearson, Kendall e Spearman. Concluiu-se que as propriedades dos painéis foram influenciadas pelo teor de adesivo, taxa de compactação e tipo de partícula derivada do resíduo lenhoso utilizado. De forma geral, os painéis confeccionados com partículas de cavacos, provenientes do resíduo rolo-resto, com maior teor de adesivo e taxa de compactação foram os que melhor atenderam aos requisitos tecnológicos exigidos pelas normas. A massa específica mostrou-se um importante índice de qualidade na avaliação dos painéis, devido à sua forte correlação com algumas propriedades físicas e mecânicas. $O$ adesivo de silicato de sódio poderá ser uma alternativa promissora na confecção de painéis de madeira do tipo aglomerado, principalmente em locais internos onde houver restrições quanto ao uso de resinas à base de formaldeído.

Palavras-chave: Propriedades físicas; Propriedades mecânicas; Silicato de sódio.

\section{Properties particleboards produced with residues of the wood mechanical processing}

\begin{abstract}
The objective of the study was to evaluate the physical and mechanical properties of agglomerated panels made with particles from residues from the mechanical processing of wood Schizolobium amazonicum Huber ex. Ducke (Paricá), with the sodium silicate adhesive as a binder. The design used was completely randomized, with 12 treatments and four repetitions, totaling 48 panels. The tests were performed according to the standards ABNT/NBR 14810-3 (2002) and ANSI/A-208.1 (1999). The averages were compared by the Tukey test for the slenderness coefficient of the particles and by the Scott-Knott test for the physical and mechanical properties, adopting $5 \%$ significance for both $(p=0.05)$. In addition, the specific mass correlation with the other tests was verified using Pearson, Kendall and Spearman coefficients. It was concluded that the properties of the panels were influenced by the adhesive content, compaction rate and type of particle derived from the woody residue used. In general, the panels made with chip particles, from the residue roll-rest, with higher adhesive content and compaction rate, were the ones that best met the technological requirements demanded by the standards. The specific mass proved to be an important quality index to the evaluation of the panels, due to its strong correlation with some physical and mechanical properties. The sodium silicate adhesive may be a promising alternative in the manufacture of particleboards, especially in indoor locations where there are restrictions for the use of resins based on formaldehyde.
\end{abstract}

Keywords: Physical properties; Mechanical properties; Sodium silicate.

Topic: Ciências Florestais

Reviewed anonymously in the process of blind peer
Received: 03/04/2021

Approved: 26/04/2021
Zaíra Morais dos Santos Hurtado de Mendoza (iD)

Universidade Federal de Mato Grosso, Brasil

http://lattes.cnpq.br/7829408545924908

http://orcid.org/0000-0002-0930-7928

zaira@ufmt.com

Pedro Hurtado de Mendoza Borges (iD

Universidade Federal de Mato Grosso, Brasil

http://lattes.cnpq.br/0310556104378957

http://orcid.org/0000-0001-7603-8775

pborges@ufmt.br

Benedito Rocha Vital (iD

Universidade Federal de Viçosa, Brasil http://lattes.cnpq.br/8240034013281714

http://orcid.org/0000-0002-3160-8356

bvital@ufv.br

d

DOI: 10.6008/CBPC2179-6858.2021.004.0005

\author{
Solange de Oliveira Araújo \\ Universidade Federal de Viçosa, Brasil \\ http://lattes.cnpq.br/8268815505508443 \\ http://orcid.org/0000-0002-6100-5353 \\ solangeeoa@yahoo.com.br \\ Pedro Hurtado de Mendoza Morais (iD) \\ Universidade Federal de Mato Grosso, Brasil \\ http://lattes.cnpq.br/9517941254638374 \\ http://orcid.org/0000-0003-2431-9262 \\ pedromorais08@hotmail.com
}

Referencing this:

MENDOZA, Z. M. S. H.; BORGES, P. H. M.; VITAL, B. R.; ARAÚJO, S. O.; MORAIS, P. H. M.. Propriedades de painéis aglomerados produzidos com resíduos do processamento mecânico da madeira. Revista Ibero Americana de Ciências Ambientais, v.12, n.4, p.46-55, 2021. DOI: http://doi.org/10.6008/CBPC2179-6858.2021.004.0005 


\section{INTRODUÇÃO}

Os resíduos de madeira são materiais combustíveis e degradáveis, classificados conforme a norma (ABNT NBR 10.004, 2004), de "Resíduos Sólidos - Classe II Não Inertes, ou seja, em condições naturais, não há riscos à saúde pública, pois não são tóxicos nem patogênicos", portanto, com potencial de reutilização.

As serrarias e laminadoras são indústrias processadoras de madeira que geram grande quantidade de resíduos, desde a entrada da tora no pátio da empresa até a saída do produto final na linha de produção, sendo este estimado entre $50 \%$ a $65 \%$ do volume de madeira bruta processada. 0 baixo coeficiente de rendimento das toras e, consequentemente, os elevados volumes de resíduos têm como causas mais relevantes o uso de equipamentos obsoletos, mão de obra desqualificada, formas inadequadas de armazenar toras e falta generalizada de atividades que visem o aproveitamento racional da matéria-prima (MENDOZA et al., 2017).

Segundo Iwakiri et al. (2000), o uso dos resíduos madeireiros provenientes das serrarias e laminadoras para produção de chapas de aglomerado é uma alternativa viável, tanto no âmbito econômico como tecnológico e ambiental, pois o volume de resíduos gerados nessas indústrias é grande. Mendes (2001) relata que as primeiras chapas de aglomerado produzidas no Brasil foram inicialmente elaboradas com resíduos de serraria, porém tiveram restrições de uso por causa das grandes reservas de florestas nativas que forneciam matéria-prima de forma ilegal. Daí et al. (2004), mencionam que as chapas de aglomerado são os derivados de madeira que apresentam maiores potencialidades para incorporar resíduos em sua fabricação, porque sua qualidade e seu processo de fabricação não são alterados.

Negrão et al. (2014), enfatizam que a utilização de resíduos lignocelulósicos na produção de painéis de madeira reconstituída, além de agregar valor, podem propiciar sustentabilidade, minimizar problemas de poluição ambiental e auxiliar no atendimento da demanda das indústrias de painéis aglomerados.

Pizzi et al. (1994) descrevem que os principais tipos de adesivos empregados na fabricação de painéis particulados são a ureia-formaldeído, o fenol-formaldeído e a melamina-formaldeído, os quais são formados por reação de polimerização. De acordo com Iwakiri (2005), a ureia-formaldeído é utilizada na produção de aglomerados que se destinam ao uso interno e o fenol-formaldeído ao uso externo. Já a melaminaformaldeído, em função do alto custo, geralmente é aplicada como fortificante em uma mistura com a ureiaformaldeído, o que confere aos painéis maior resistência à água. O mesmo autor descreve que dos três adesivos, a ureia-formaldeído tem a preferência em mais de $90 \%$ dos painéis direcionados para o setor moveleiro, devido ao baixo custo, facilidade de manuseio, cura rápida e formação da linha de cola imperceptível, porque o adesivo fica incolor.

Contudo, Marra (1992) ressalta que os adesivos tradicionalmente utilizados em madeiras e seus subprodutos, emitem formaldeído e que são derivados do petróleo, uma fonte de matéria-prima não renovável, representando, portanto, uma preocupação econômica, ambiental e de saúde aos seus usuários. Além disso, segundo Haselein et al. (2002), os adesivos derivados de petróleo podem onerar em até 30\% o custo de produção. Assim, a substituição desses adesivos por outros tipos de resinas poderia trazer grandes 
benefícios para as indústrias e seus consumidores.

O adesivo de silicato de sódio é um composto químico inorgânico, empregado na indústria de conversão do papel, tubos, tubetes e embalagens (SHREVE, 1980). Conforme Lima Filho (2009), o silicato de sódio é uma solução aquosa de dióxido de silício $\left(\mathrm{SIO}_{2}\right)$ e oxido de sódio $\left(\mathrm{Na}_{2} \mathrm{O}\right)$, as variações na relação ponderal entre ambos os óxidos e o teor de sólidos da solução, permite obter formulações diferenciadas de silicatos de sódio, com características específicas para utilização nos diversos segmentos de mercado. Sendo assim, os silicatos são produtos químicos versáteis, com aplicações abrangentes dentro dos setores químicos, farmacêuticos, perfumaria, papel, agricultura e pecuária.

Nesse contexto, o objetivo do estudo foi avaliar as propriedades físicas e mecânicas de painéis aglomerados confeccionados com partículas dos resíduos do processamento mecânico da madeira Paricá (Schizolobium amazonicum Huber ex. Ducke), aglutinados com resina à base de silicato de sódio, visando a formação de um produto com características ambientalmente mais sustentáveis.

\section{MATERIAIS E MÉTODOS}

O material lignocelulósico empregado foram resíduos na forma de lâminas, rolo-resto e costaneiras, da madeira de Paricá (Schizolobium amazonicum Huber ex. Ducke), coletados em empresas laminadoras, localizadas no estado do Pará.

Após a coleta, os resíduos foram processados individualmente em um moinho do tipo martelo utilizando-se uma peneira com malha de 1,0 mm para classificação das partículas de acordo com seu formato. Tendo como base a classificação, os resíduos de lâminas deram origem às partículas de lâminas, o rolo-resto originou as partículas de cavacos e as costaneiras as partículas de maravalhas. Em seguida, os materiais foram secos até $5 \%$ de umidade em estufa de circulação forçada, sendo sequencialmente aferidas suas dimensões com paquímetro.

O aglutinante utilizado na confecção dos painéis foi o silicato de sódio na forma líquida, com propriedades adesivas de $45 \%$ para teor de sólidos, tempo de gel a $121^{\circ} \mathrm{C}$ de 7 minutos, $\mathrm{pH} 12,2$ e viscosidade de 750 cP. A sua aplicação foi de forma pulverizada, nos teores de $8 \%$ e $10 \%$ em relação à massa seca de partículas.

A pré-prensagem do colchão foi manual e a prensagem final foi realizada em prensa mecânica de laboratório, aplicando-se pressão específica de 3,2 MPa por 10 minutos e temperatura de $170{ }^{\circ} \mathrm{C}$. As medidas absolutas dos painéis foram $40 \times 40 \times 1,0 \mathrm{~cm}$ (comprimento, largura e espessura), com massa específica nominal de $540 \mathrm{~kg} \cdot \mathrm{m}^{-3}$ e $670 \mathrm{~kg} \cdot \mathrm{m}^{-3}$ para as taxas de compactação de 1,7 e 2,1 respectivamente. Após a prensagem, os painéis foram climatizados à temperatura de $20{ }^{\circ} \mathrm{C}( \pm 2)$ e umidade relativa de $65 \%( \pm 3)$ até estabilização. Em seguida realizaram-se os ensaios físicos e mecânicos, tendo como referência as normas ABNT/NBR 14810-3 (2002) e ANSI/A-208.1(1999).

O delineamento utilizado foi o inteiramente casualisado, com quatro repetições e 12 tratamentos, provenientes de três tipos de partículas residuais (lâminas, cavacos e maravalhas), dois teores de adesivos (8\% e 10\%) e duas taxas de compactação $(1,7$ e 2,1$)$, conforme discriminado na Tabela 1. 
Tabela 1: Tratamentos experimentais.

\begin{tabular}{llll}
\hline Tratamentos & Tipos de partículas & Teores de adesivo (\%) & Taxas de compactações \\
\hline T1 & Lâmina & 8 & 1,7 \\
T2 & Lâmina & 10 & 1,7 \\
T3 & Lâmina & 8 & 2,1 \\
T4 & Lâmina & 10 & 2,1 \\
T5 & Cavaco & 8 & 1,7 \\
T6 & Cavaco & 10 & 1,7 \\
T7 & Cavaco & 8 & 2,1 \\
T8 & Cavaco & 10 & 2,1 \\
T9 & Maravalha & 8 & 1,7 \\
T10 & Maravalha & 10 & 1,7 \\
T11 & Maravalha & 8 & 2,1 \\
T12 & Maravalha & 10 & 2,1 \\
\hline
\end{tabular}

Para atender a normalidade e homocedasticidade dos dados aplicaram-se, respectivamente, os testes Shapiro-Wilk e Bartlett para 95\% de probabilidade. Após a verificação dessas premissas, realizou-se a análise de variância por meio do teste Fischer $(F)$. Nos casos em que o valor de $F$ foi significativo $(p<0,05)$, as médias foram comparadas pelo teste Tukey para o coeficiente de esbeltez das partículas e pelo teste de Scott-Knott para as propriedades físicas e mecânicas, adotando-se $5 \%$ de significância para ambos $(p \leq 0,05)$. Além disso, foi analisada a correlação da massa específica com as demais propriedades utilizando-se os coeficientes de Pearson, Kendall e Spearman. Todos os procedimentos estatísticos foram executados com auxílio do programa $R$ (R CORE TEAM, 2019).

\section{RESULTADOS E DISCUSSÃO}

\section{Geometria das partículas}

Na Tabela 2 são apresentadas as dimensões das partículas geradas a partir dos diferentes tipos de resíduos. Observa-se que o coeficiente de esbeltez das partículas do tipo lâmina (resíduo de lâmina) e maravalha (resíduo de costaneiras) não diferiram entre si, porém, as partículas do tipo cavaco (resíduo de rolo-resto) apresentaram um coeficiente significativamente menor em relação às demais.

Tabela 2: Valor médio das dimensões das partículas provenientes dos três tipos de resíduos.

\begin{tabular}{llll}
\hline \multirow{2}{*}{ Tipos de partículas } & \multicolumn{2}{l}{ Dimensões médias das partículas } & \multirow{2}{*}{ Coeficiente de esbeltez } \\
\cline { 2 - 3 } & Comprimento $(\mathrm{mm})$ & 0,95 & $10,89 \mathrm{a}$ \\
\hline Lâmina & 10,35 & 0,82 & $8,74 \mathrm{~b}$ \\
Cavaco & 7,17 & 0,51 & $10,73 \mathrm{a}$ \\
Maravalha & 5,47 & $\mathrm{~mm})$ & \\
\hline
\end{tabular}

Médias seguidas por letras iguais nas colunas, não diferem estatisticamente pelo Teste de Tukey.

O coeficiente de esbeltez obtido para as partículas oriundas de lâminas $(10,89)$ foi similar àquele relatado por Bianche et al. (2012), cujo valor foi de 10,9. Por outro lado, as partículas derivadas de cavaco apresentaram coeficiente de 8,74 que foi semelhante aos de Naumann et al. (2008), com valor de 8,82, os quais diferiram de Colli et al. (2010) que observaram um coeficiente igual a 7,09. Já os valores dos coeficientes das partículas produzidas com maravalha $(10,73)$ diferiram daqueles observados por Naumann et al. (2008), que foi de 15,97 . Estas diferenças indicam que a geometria das partículas pode ser afetada pelo formato da matéria prima que as produziu. Assim, é necessário o controle da forma e dimensão da matéria prima para que se possam gerar partículas com geometria adequada uma vez que irão influenciar a área superficial 
específica e, consequentemente, no consumo de adesivo e nas propriedades das chapas (KELLY, 1977). Conforme Vital et al. (1992), partículas longas e finas produzem chapas com maior resistência à flexão estática e maior estabilidade dimensional, enquanto chapas fabricadas com partículas curtas e espessas, conferem as chapas resistência à tração perpendicular ou ligação interna, mais elevada.

\section{Propriedades físicas}

Conforme o teste de Scott-Knott $(p<0,05)$, houve diferença significativa entre os tratamentos para todas as propriedades físicas analisadas (Tabela 3).

Tabela 3: Valores médios das propriedades físicas dos painéis em função dos tratamentos.

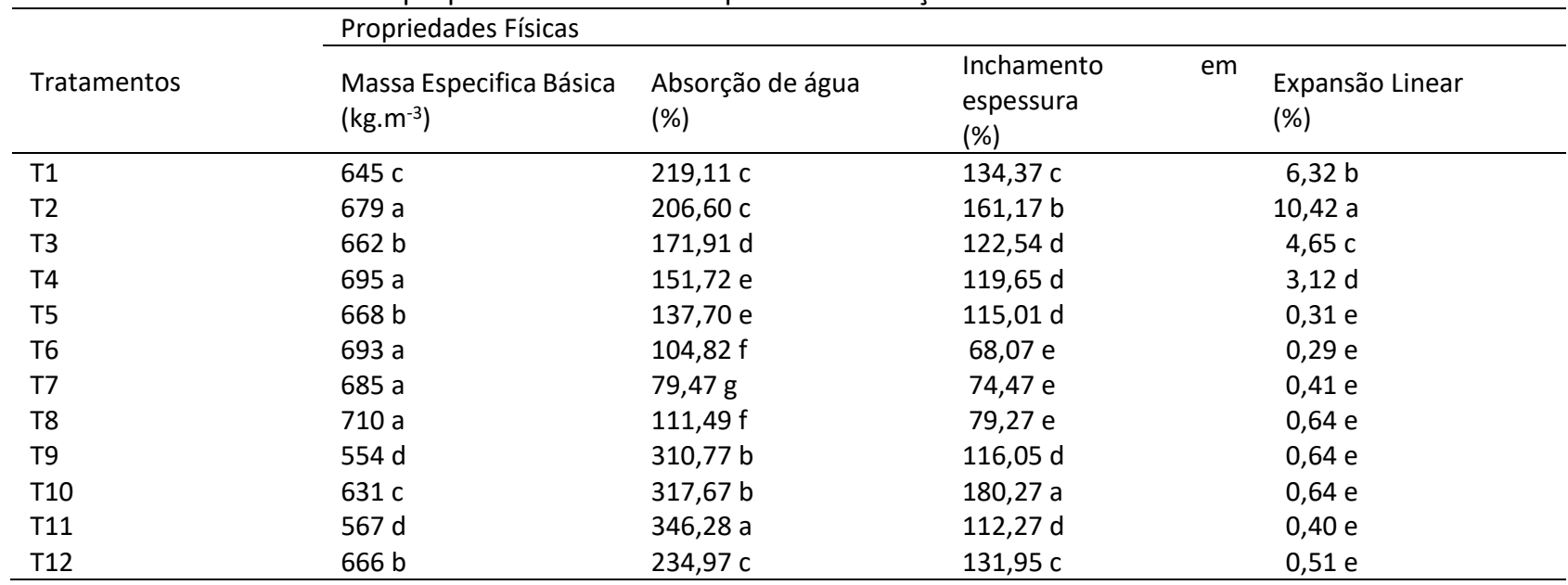

Médias seguidas por letras iguais nas colunas, não diferem estatisticamente pelo Teste de Scott-Knott.

De acordo com os dados de referência (551 kg.m $\mathrm{m}^{-3}$ a $750 \mathrm{~kg} \cdot \mathrm{m}^{-3}$ ) da norma ABNT- NBR 14810-2:2002, os painéis foram classificados como de média massa específica, com valores de $554 \mathrm{~kg} \cdot \mathrm{m}^{-3}$ a $710 \mathrm{~kg} \cdot \mathrm{m}^{-3}$. Verifica-se que os painéis confeccionados com lâminas e cavacos apresentaram as maiores médias de massa específica para quaisquer teores de adesivos e taxa de compactação. Contudo, para aqueles produzidos com partículas originadas de maravalhas a maior massa específica foi obtida no tratamento $\mathrm{T} 12$, com $10 \%$ de adesivo e taxa de compactação de 2,1. Conforme Lengowski et al. (2021), a massa específica de painéis reconstituídos está relacionada à densidade da matéria-prima, ao conteúdo de sólidos do adesivo, bem como à quantidade de resina presente na linha de cola.

A absorção de água, para duas horas de imersão, teve influência do tipo de partícula sendo maior para os painéis fabricados com maravalhas na taxa de compactação de 1,7 em ambos teores de adesivo (T9, T10), e para a taxa de 2,1 com 8\% de adesivo (T11). Por outro lado, as menores absorções foram observadas para os painéis provenientes das partículas de cavacos com 10\% de adesivo e taxa de 1,7 (T6) bem como, na taxa de 2,1 para os dois teores de adesivo $(T 7, T 8)$. Todos os tratamentos apresentaram médias de absorção de água (2h) acima do permitido pela norma ANSI/A 208.1 (1999), cujos valores devem estar abaixo de 10\%. Torkaman (2010), em sua pesquisa com painéis aglomerados com madeira de Paricá, também encontrou valores elevados de absorção de água para 2 horas (136,47\%).

Naumann et al. (2008), trabalhando com chapas de aglomerado, fabricadas com eucalipto e resíduos de Paricá, reconstituídas com adesivo à base de ureia-formaldeído (8\%), observaram que a absorção de água 
por 2 horas não sofreu influência da dimensão da partícula. Colli et al. (2010) e Bianche et al. (2012), trabalhando com a madeira de Paricá para confecção de aglomerados, encontraram efeito significativo do teor de adesivo com a absorção de água. Tal efeito não foi verificado nessa pesquisa.

As menores médias de inchamento em espessura, após duas horas de imersão em água, foram obtidos nos painéis produzidos com partículas provenientes de cavacos e com $10 \%$ de adesivo e taxa de compactação de 1,7 (T6) e também na taxa de 2,1 independente do teor de adesivo (T7, T8). Contudo, todos os valores ficaram acima do permitido na norma ABNT- NBR 14810-2:2002, que estabelece um inchamento máximo de $8 \%$. Independentemente do tratamento, os valores de inchamento observados neste trabalho, ficaram acima daqueles obtidos por Colli et al. (2010), Naumann et al. (2008), Bianche et al. (2012), Torkaman (2010), Iwakiri et al. (2010).

$\mathrm{Na}$ expansão linear os menores valores foram encontrados para os painéis confeccionados com partículas provenientes de cavacos e maravalhas, para qualquer teor de adesivo e taxa de compactação (T5, $\mathrm{T} 6, \mathrm{~T} 7, \mathrm{~T} 8, \mathrm{~T} 9, \mathrm{~T} 10, \mathrm{~T} 11, \mathrm{~T} 12)$. A maior expansão foi obtida para aqueles fabricadas com partículas originadas de lâminas, $10 \%$ de adesivo e taxa de 1,7 (T2).

Nessa pesquisa, somente os painéis produzidos com partículas provenientes de cavacos nos dois teores de adesivo e taxa de compactação de 1,7 $(T 5, T 6)$ tiveram médias de expansão linear $(0,31 \%$ e 0,29\%) abaixo do permitido pela norma ANSI/A-208.1 (1999), que estabelece o máximo de 0,35\%. Esses valores foram inferiores ao obtido por Naumann et al. (2008) que foi de 0,43\%, ao analisarem painéis aglomerados com resíduos de Paricá e adesivo à base de ureia-formaldeído.

Ressalta-se que os painéis desse estudo não receberam parafina, o que, provavelmente, contribuiu para o aumento de alguns resultados de expansão linear, assim como das demais propriedades físicas analisadas anteriormente. A heterogeneidade dessas propriedades também pode ser devida à origem dos resíduos, pois cada material veio de uma parte específica da madeira, a qual apresentava característica anatômica distinta. As lâminas tinham células do cerne e do alburno, sendo esse último em maior quantidade, as costaneiras possuíam basicamente alburno, já o rolo-resto apresentava somente medula. Em todos os materiais ocorreu predominância de tecido parenquimático, composto por células de paredes finas e lúmen grande, provavelmente, isso conferiu aos resíduos alta porosidade e permeabilidade.

Outro ponto relevante dentro da discussão dessa pesquisa é que as comparações foram feitas com trabalhos que utilizaram ureia-formaldeído como adesivo, que apresenta menor solubilidade em água do que $\mathrm{o}$ adesivo de silicato de sódio.

\section{Propriedades mecânicas}

Na Tabela 4 são apresentadas algumas das principais propriedades mecânicas dos painéis, que foram desenvolvidas nos ensaios de tração perpendicular, flexão estática, dureza Janka e arrancamento de parafuso. Nessa Tabela, constata-se que houve diferença significativa entre os tratamentos para todas as propriedades mecânicas, conforme o teste de Scott-Knott $(p<0,05)$. 
Tabela 4: Valores médios das propriedades mecânicas dos painéis em função dos tratamentos.

\begin{tabular}{|c|c|c|c|c|c|}
\hline \multirow{3}{*}{ Tratamentos } & \multicolumn{5}{|c|}{ Propriedades Mecânicas } \\
\hline & \multirow{2}{*}{$\begin{array}{l}\text { Tração } \\
\text { Perpendicular } \\
(\mathrm{MPa})\end{array}$} & \multicolumn{2}{|c|}{$\begin{array}{l}\text { Flexão Estática } \\
\text { (MPa) }\end{array}$} & \multirow{2}{*}{$\begin{array}{l}\text { Dureza Janka } \\
\text { (MPa) }\end{array}$} & \multirow{2}{*}{$\begin{array}{l}\text { Arrancamento } \\
\text { de Parafuso } \\
\text { (N) }\end{array}$} \\
\hline & & MOR & MOE & & \\
\hline T1 & $0,1015 \mathrm{c}$ & $3,62 b$ & $320,40 \mathrm{~b}$ & $1,27 \mathrm{c}$ & $581,04 \mathrm{~d}$ \\
\hline $\mathrm{T} 2$ & $0,0772 \mathrm{c}$ & $4,94 \mathrm{~b}$ & $455,98 \mathrm{~b}$ & $1,39 \mathrm{~b}$ & $856,86 \mathrm{c}$ \\
\hline T3 & $0,1607 \mathrm{~b}$ & $6,32 \mathrm{a}$ & 530,75 a & 1,55 a & $824,98 \mathrm{c}$ \\
\hline T4 & $0,1518 b$ & $4,94 \mathrm{~b}$ & $588,52 \mathrm{a}$ & 1,59 a & 1363,39 a \\
\hline T5 & 0,3367 a & $6,29 a$ & 719,59 a & $1,38 \mathrm{~b}$ & $1102,02 b$ \\
\hline T6 & 0,3274 a & 5,63 a & $621,92 \mathrm{a}$ & 1,47 a & $1209,90 \mathrm{~b}$ \\
\hline T7 & 0,2593 a & $6,35 \mathrm{a}$ & 690,77 a & $1,48 \mathrm{a}$ & $1133,89 \mathrm{~b}$ \\
\hline T8 & $0,3034 \mathrm{a}$ & $6,73 a$ & $644,22 \mathrm{a}$ & $1,57 \mathrm{a}$ & $1127,76 \mathrm{~b}$ \\
\hline T9 & $0,0717 \mathrm{c}$ & 7,17 a & 546,47 a & $0,58 \mathrm{e}$ & $237,81 \mathrm{f}$ \\
\hline T10 & $0,0384 \mathrm{c}$ & $3,44 b$ & $354,09 \mathrm{~b}$ & $1,06 \mathrm{~d}$ & $433,94 \mathrm{e}$ \\
\hline T11 & $0,0253 c$ & $3,31 b$ & $442,66 \mathrm{~b}$ & $0,48 \mathrm{e}$ & $203,49 f$ \\
\hline T12 & $0,0731 \mathrm{c}$ & 5,65 a & $597,00 \mathrm{a}$ & $1,35 \mathrm{~b}$ & $625,17 \mathrm{~d}$ \\
\hline
\end{tabular}

Médias seguidas por letras iguais nas colunas, não diferem estatisticamente pelo Teste de Scott-Knott.

A resistência à tração perpendicular de todas os painéis não atingira ao mínimo exigido pela norma regulamentadora ABNT NBR 14810-2:2002, (0,35 MPa). Porém, os painéis confeccionados com partículas de cavacos apresentaram os valores mais elevados dessa propriedade ficando bem próximos ao requerido pela normativa. Para alguns tratamentos, os valores de tração perpendicular foram superiores à média de 0,15 Mpa, encontrada por Torkaman (2010) e de 0,28 MPa relatados por Colli et al. (2010). Porém, todos os tratamentos apresentaram valores médios inferiores aos obtidos por Naumann et al. (2008), os quais foram de 0,46 MPa (maravalhas) e de 0,58 MPa (cavacos) para painéis feitos exclusivamente de Paricá, com 8\% de adesivo à base de ureia-formaldeído. Segundo Iwakiri (2005), o tamanho da partícula influencia a resistência à tração dos painéis, pois partículas menores apresentam maior área superficial de contato, absorvem mais adesivo e se aderem com mais facilidade, implicando assim em uma maior força de ligação interna.

Os valores médios da resistência à flexão estática, representada pelo módulo de ruptura (MOR) e módulo de elasticidade (MOE), também ficaram abaixo do mínimo estabelecido na norma ANSI A 208.1. (1999), de $11 \mathrm{MPa}$ e $1725 \mathrm{MPa}$, respectivamente. Contudo, foram superiores aos valores encontrados por Torkaman (2010) e Colli et al. (2010).

Todos os painéis atingiram o valor mínimo de dureza Janka requerido pela norma ABNT NBR 148102:2002 (1 MPa), exceto os fabricados com partículas provenientes de maravalhas com $8 \%$ de adesivo. Independente da condição experimental, os valores encontrados foram superiores aos relatados por Naumann et al. (2008), cujos valores médios de dureza Janka foram de 0,33 MPa e 0,27 MPa para painéis produzidos, respectivamente, com partículas derivadas de maravalhas e de cavacos de Paricá.

A resistência ao arrancamento de parafuso foi superior ao mínimo estabelecido pela norma ANSI A 208.1. (1999), (1100N) nas chapas confeccionadas com partículas provenientes de lâminas e com $10 \%$ de adesivo, na taxa de compactação de 2,1, bem como para as chapas confeccionadas com partículas provenientes de cavacos. Colli et al. (2010) encontraram valores respectivamente de $200 \mathrm{~N}$ e $290 \mathrm{~N}$, para painéis aglomerados feitos somente de Paricá, com $6 \%$ e $8 \%$ de adesivo ureia-formaldeído. Todos os resultados dessa pesquisa ficaram acima desses valores, exceto para as chapas elaboradas com maravalhas no teor de $8 \%$ de adesivo nas duas taxas de compactação. Naumann et al. (2008), em seus estudos com 
chapas de aglomerado, produzidas com madeira de Paricá e com 7\% de adesivo ureia-formaldeído, verificaram que a resistência ao arrancamento de parafuso apresentou valores de 7,10 $\mathrm{N}$ e de 6,6 N, quando foram usadas partículas derivadas de maravalhas e de cavacos, respectivamente. Os resultados dessa propriedade encontrados nessa pesquisa foram maiores do que esses valores, independentemente da condição experimental analisada.

\section{Correlação entre as propriedades}

As propriedades físicas e mecânicas dos painéis mostraram correlação com a massa específica, de acordo com os coeficientes de Pearson, Kendall e Spearman (Tabela 5).

Tabela 5: Coeficientes de correlação da massa específica com outras propriedades físicas e mecânicas.

\begin{tabular}{|c|c|c|c|c|}
\hline \multirow{2}{*}{ Propriedade } & \multirow{2}{*}{ Ensaio } & \multicolumn{3}{|c|}{ Coeficiente de correlação } \\
\hline & & Pearson & Kendall & Spearman \\
\hline \multirow{3}{*}{ Física } & Absorção de água (\%) & $-0,8178$ & $-0,5851$ & $-0,7861$ \\
\hline & $\begin{array}{l}\text { Inchamento } \\
\text { espessura (\%) }\end{array}$ & $-0,4461$ & $-0,4606$ & $-0,6003$ \\
\hline & Expansão linear (\%) & $-0,1637$ & $-0,0071$ & $-0,0217$ \\
\hline \multirow{5}{*}{ Mecânica } & $\begin{array}{l}\text { Tração perpendicular } \\
\text { (MPa) }\end{array}$ & 0,5327 & 0,4532 & 0,6315 \\
\hline & $\begin{array}{l}\text { Módulo de ruptura- } \\
\text { MOR (MPa) }\end{array}$ & 0,2644 & 0,2771 & 0,3645 \\
\hline & $\begin{array}{l}\text { Módulo } \\
\text { elasticidade-MOE } \\
\text { (MPa) }\end{array}$ & 0,3472 & 0,2784 & 0,3973 \\
\hline & Dureza Janka (MPa) & 0,8957 & 0,5816 & 0,7439 \\
\hline & $\begin{array}{l}\text { Arrancamento de } \\
\text { Parafuso }(N)\end{array}$ & 0,8313 & 0,6116 & 0,8090 \\
\hline
\end{tabular}

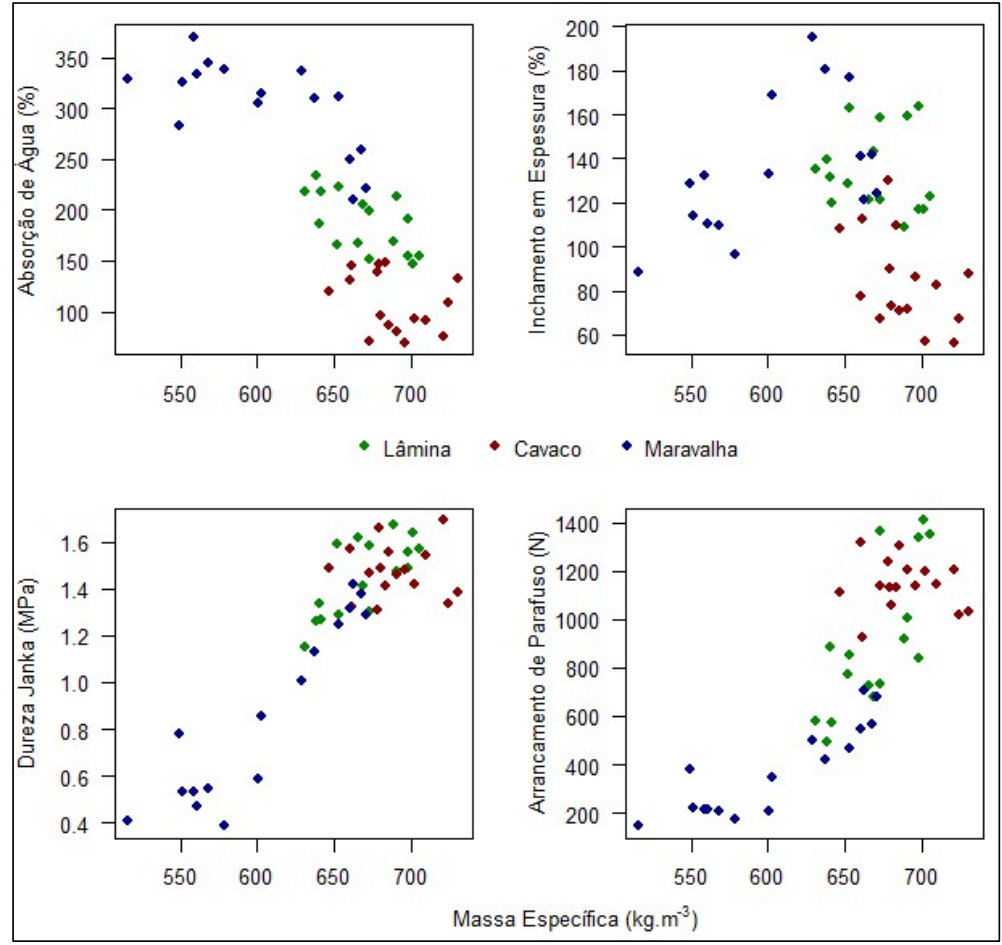

Figura 1: Diagrama de dispersão das propriedades em função da massa específica.

Dentre os ensaios realizados, constatou-se que a propriedade física absorção de água e as propriedades mecânicas dureza Janka e arrancamento de parafuso apresentaram forte correlação. Por outro 
lado, as correlações com o inchamento em espessura e com a tração perpendicular foram fracas, sendo muito baixa para as demais propriedades. Esses resultados consolidam os preceitos de que a massa específica é um índice de qualidade importante na avaliação de produtos madeireiros.

Em seguida, tomando-se como referência os dois melhores índices de correlação dos ensaios físicos e mecânicos, elaboraram-se os diagramas de dispersão, em função da massa específica para os três tipos de partículas (Figura 1).

Nessa Figura, observa-se que a massa específica foi inversamente proporcional à absorção de água e ao inchamento em espessura, porém, foi diretamente proporcional à dureza Janka e ao arrancamento de parafuso. De forma geral, independentemente da taxa de compactação e do teor de adesivo, os painéis elaborados com partículas de lâminas e cavacos evidenciaram menor variabilidade.

\section{CONCLUSÕES}

As propriedades físicas e mecânicas dos painéis aglomerados foram influenciadas pelo teor de adesivo, taxa de compactação e tipo de partícula derivada do resíduo lenhoso utilizado. Os painéis confeccionados com partículas de cavacos, provenientes do resíduo rolo-resto, com maior teor de adesivo e maior taxa de compactação, foram os que melhor atenderam aos requisitos tecnológicos exigidos pela norma regulamentadora brasileira.

A massa específica mostrou-se um importante índice de qualidade para a avaliação dos painéis, devido à sua forte correlação com algumas propriedades físicas e mecânicas. $\mathrm{O}$ adesivo de silicato de sódio poderá ser uma alternativa promissora na confecção de painéis de madeira do tipo particulado, principalmente em locais internos onde houver restrições quanto ao uso de resinas à base de formaldeído.

\section{REFERÊNCIAS}

ANS. American National Standard. Mat-formed wood particleboard: Specification ANSI/A 208.1. 1999.

Gaithersburg: National Particleboard Association, 1999.

ABNT. Associação Brasileira de Normas Técnicas. NBR 14810-1,2,3. Chapas de madeira aglomerada. ABNT, 2002.

ABNT. Associação Brasileira de Normas Técnicas. NBR 10004. Resíduos sólidos: classificação. Rio de Janeiro, 2004.

BIANCHE, J. J.; CARNEIRO, A. C. O.; VITAL, B. R.; PEREIRA, F. A.; SANTOS, R. C.; SORATTO, D. N.. Propriedades de painéis aglomerados fabricados com partículas de eucalipto (Eucalyptus urophylla), paricá (Schizolobium amazonicum) e vassoura (Sida spp.). Cerne, Lavras, v.18, n.4, p.623-630, 2012. DOI: https://doi.org/10.1590/S010477602012000400012

COLLI, A. VITAL, B. R.; CARNEIRO, A. C. O.; SILVA, J. C.; CARVALHO, A. M. M. L.; DELLA LUCIA, R. M.. Propriedades de chapas fabricadas com partículas de madeira de paricá (Schyzolobium amazonicum Huber ex. Ducke) e fibras de coco (Cocos nucifera L.). Revista Árvore, Viçosa, v.34, n.2, p.333-338, 2010. DOI: http://dx.doi.org/10.1590/s010067622010000200016
DAÍ, C.; WASYLCIW, W.; JIN, J.. Comparison of the pressing behaviour of Wood particleboard and strawboard. Wood Science Technology, n. 38, p.529-537, 2004. DOI: https://doi.org/10.1007/s00226-004-0256-2

HASELEIN, C. R.; CALEGARI, L.; BARROS, M. V.; HACK, C.; HILLIG, E.; PAULESKI, D. T.; POZERRA, F.. Resistência mecânica e à umidade de painéis aglomerados com partículas de madeira de diferentes dimensões. Ciência Florestal, Santa Maria, v.12, n.2, p.127-134, 2002. DOI: https://doi.org/10.5902/198050981687

IWAKIRI, S.; CUNHA, A. B.; ALBUQUERQUE, C. E. C.; GORNIAK, E.; MENDES, L. M.. Resíduos de serrarias na produção de painéis de madeira aglomerada de eucalipto. Scientia Agraria, Curitiba, v.1, n.2, p.23-28, 2000.

IWAKIRI, S.. Painéis de madeira reconstituída. 2 ed. Curitiba: Fundação de Pesquisas Florestais do Paraná, 2005.

IWAKIRI, S.; ZELLER, F.; PINTO, J. A.; RAMIREZ, M. G. L.; SOUZA, M. M.; SEIXAS, R.. Avaliação do potencial de utilização da madeira de Schizolobium amazonicum "Paricá" e Cecropia hololeuca "Embaúba" para produção de painéis 
aglomerados. Acta Amazônica, v.40, n.2, p.303-308, 2010. DOI: https://doi.org/10.1590/S0044-59672010000200008

KELLY, M. W.. Critical Literature Review of Relationships Between Processing Parameters and Physical Properties of Particleboard. USDA Forest Service General Technical Reports, v.10, p.65, 1977.

LENGOWSKI, E. C.; BONFATTI JUNIOR, E. A.; DALLO, R.; NISGOKI, S.; MATTOS, J. L. M.; PRATA, J. G.. Nanocellulosereinforced phenol-formaldehyde resin for plywood panel production. Maderas-Ciencia y Tecnologia, v.23, n.5, p.1-10, 2021. DOI: http://dx.doi.org/10.4067/s0718$221 \times 2021000100405$

LIMA FILHO, O. F.. História e Uso do Silicato de Sódio na Agricultura. Dourados: Embrapa Agropecuária Oeste, 2009.

MARRA, F. S.. Technology of wood bonding: Principles in practice. 3 ed. New York: Van Nostrand Reinhold, 1992.

MENDES, L. M.. Pinus spp. na produção de painéis de partículas orientadas (OSB). Tese (Doutorado) Universidade Federal do Paraná, Curitiba, 2001.

MENDOZA, Z. M. S. H.; BORGES, P. H. M.; PIERIN, L. C.. Nativa, Sinop, v.5, p.568-573, 2017. DOI:

https://doi.org/10.31413/nativa.v5i7.4430

NAUMANN, R. B.; VITAL, B.; CARNEIRO, A. C. O.; DELLALUCIA, R. M.; SILVA, J. C.; CARVALHO, A. M. M. L.; COLLI, A.. Propriedades de chapas fabricadas com partículas de madeira de Eucalyptus urophylla S. T. Blake e de Schizolobium amazonicum Herb. Revista Árvore, Viçosa, v.32, n.6, p.1143-1150, 2008. DOI: https://doi.org/10.1590/S0100-67622008000600020

NEGRÃO, W. H.; SILVA, S. A. M.; CHRISTOFORO, A. L.; LAHR, F. A. R.. Painéis aglomerados fabricados com mistura de partículas de madeiras tropicais. Ambiente Construído, v.14, n.3, p.103-112, 2014.

DOI: https://doi.org/10.1590/S1678-86212014000300008

PIZZI, A.; MITTAL, K. L. Handbook of adhesive technology. 2 ed. New York: Marcell Deckker, 1994.

R CORE TEAM. R Development Core Team. R: A language and environment for statistical computing. Vienna: R Foundation for Statistical Computing. ISBN: 3900051-07-0. 2019.

SHREVE, R. N.. Indústrias de Processos Químicos. 2 ed. Rio de Janeiro: Guanabara, 1980.

TORKAMAN, J.. Improvement of bondability in rice husk particleboard made with sodium silicate. In: SECOND INTERNATIONAL CONFERENCE ON SUSTAINABLE CONSTRUCTION MATERIAL AND TECHNOLOGIES, 2. Anais. University of Wisconsin Milwaukee, Centre for By-products Utilization, 2010. p.125-132.

VITAL, B. R.; HASELEIN, C. R.; DELLA-LUCIA, R. M.. Efeito da geometria das partículas nas propriedades das chapas de madeira aglomerada de Eucalyptus grandis (Hill ex-Maiden). Revista Árvore, Viçosa, v.16, n.1, p.88-96, 1992.

A CBPC - Companhia Brasileira de Produção Científica (CNPJ: 11.221.422/0001-03) detém os direitos materiais desta publicação. Os direitos referem-se à publicação do trabalho em qualquer parte do mundo, incluindo os direitos às renovações, expansões e disseminações da contribuição, bem como outros direitos subsidiários. Todos os trabalhos publicados eletronicamente poderão posteriormente ser publicados em coletâneas impressas sob coordenação da Sustenere Publishing, da Companhia Brasileira de Produção Científica e seus parceiros autorizados. Os (as) autores (as) preservam os direitos autorais, mas não tem permissão para a publicação da contribuição em outro meio, impresso ou digital, em português ou em tradução. 